\title{
Dispersion and fall out of heavier particles
}

\author{
P. Astrup \\ DTU - Technical University of Denmark, Department of Wind Energy, Frederiksborgvej 399, DK 4000 Roskilde, Denmark.
}

\begin{abstract}
Nuclear accidents have so far been expected to release gasses and aerosols, but other CBRN events and also nuclear accidents with release of core particles can be expected to also release larger particles to the atmosphere. If not so large and heavy, that they fall to the ground immediately they may like gasses and aerosols be transported more or less far by the wind. The present paper focuses on the growth of plumes of such particles larger and heavier than aerosols and transported by the wind. Implementation in existing decision support puff dispersion programs requires a parameterization of this growth, and two reasonable describing parameterizations have been found, one in the literature, one proposed here, and both are compared to experimental work found in the literature. The parameterization from the literature has been implemented in the dispersion program RIMPUFF, which has subsequently shown that the effect on fall out to a large extent overrules the effect on the dispersion of such particles.
\end{abstract}

Keywords: dispersion simulation / heavy particles / decision support / ARGOS / RODOS

\section{Introduction}

Atmospheric dispersion is first of all a consequence of the atmospheric turbulence the effect of which surpasses the molecular diffusion by a high factor. Turbulence can be thought of as a superposition of a large range of vortices setting up oscillations of a huge sequence of wave numbers and amplitudes and in all directions. Diffusion of gasses and aerosols has been modelled for a long time, diffusion of larger and heavier particles than aerosols has also been studied for many years and models have been proposed based on the tracking of a number of individual particles through turbulent structures, but for implementation in existing decision support atmospheric dispersion programs based on plume and puff models, a parameterization is required, not a model based on the tracking of particles.

A thorough description of this work can be found in Astrup (2016).

\section{Theory}

Taylor (1922) developed the theory for dispersion of fluid points in stationary homogeneous turbulence. Atmospheric turbulence is neither stationary nor homogeneous, but Taylor's findings are anyway used in modelling of atmospheric dispersion. Aerosols are particles of dimensional order $1 \mathrm{micron}, 10^{-6} \mathrm{~m}$, and of mass density like water, $1000 \mathrm{~kg} \mathrm{~m}^{-3}$. With a free fall velocity of approximately $0.00003 \mathrm{~m} \mathrm{~s}^{-1}$ they can be expected to follow the atmospheric flow slavishly and disperse like elements of air. Particles larger and heavier than aerosols cannot be expected to follow the atmospheric turbulence in quite the same manner, both due to their larger inertia (the inertia effect) and due to the gravity driven increased relative velocity giving rise to the "crossing trajectories" effect, first studied and so named by Yudine (1959) and representing the effect of particles traversing eddies in less time than the eddy life time.

\section{Parameterizations}

Many investigations of particle dispersion, but not many parameterizations, have been made during the years: measurements in wind tunnels (e.g. Snyder and Lumley, 1971; Wells and Stock, 1983), measurements outdoor (e.g. Csanady, 1964), models tracing a number of particles describing the interaction with turbulence in different ways (e.g. Gosman and Ioannides, 1981; Shuen et al., 1983; Walklate, 1987; Ichard and Melheim, 2010), and analytical reasoning revealing increased knowledge and reasonable parameterizations (e.g. Csanady, 1963).

\subsection{Csanady parameterization}

Csanady (1963) finds that due to the relative long time scales of atmospheric turbulence the inertia effect is negligible even for particles as large as 500 microns, meaning that the standard deviation for the turbulent velocity components for the particles can be set equal to that of fluid points. This leads him to equations for the dispersion coefficient of particles relative to that for the fluid points only depending on the fluid vertical turbulence, the particle free fall velocity, and a parameter $\beta$ dependent also on turbulence time and length scales.

\subsection{Astrup parameterization}

Another formulation modelling the "crossing trajectory" effect is also investigated. It takes the particle turbulent time scale as minimum of the fluid turbulent time scale and the fluid turbulent length scale divided by the particle free fall velocity. 


\section{Fitting and tests against experiments}

For the Csanady parameterization $\beta$ has here not been modelled but has been fitted $(\beta=0.17)$ against the wind tunnel experiments of Wells and Stock (1983), and then tested against the wind tunnel experiments of Snyder and Lumley (1971) and the free fall experiments of Csanady (1964). The Astrup parameterization has been tested against all the experiments. " $k-\varepsilon$ " theory has been used to determine turbulence length and time scales in the wind tunnel experiments, and Carruthers et al. (1992) have been applied for the Csanady experiment modelling.

\subsection{Wells and Stock}

Horizontal wind tunnel with grid generated turbulence and an electrical field to control the vertical speed of the suspended charged particles: glass spheres of 5 respectively 57 micron diameter. The results can be found in Astrup (2016).

\subsection{Snyder and Lumley}

Vertical wind tunnel with grid generated turbulence and just gravitational particle drift. Four kinds of particles, two with equal size, two with equal fall speed: hollow glass beads: diameter $46.5 \mu \mathrm{m}$, density $260 \mathrm{~kg} \mathrm{~m}^{-3}$, free fall speed $0.0165 \mathrm{~m} \mathrm{~s}^{-1}$; solid glass beads: $87.0 \mu \mathrm{m}, 2500 \mathrm{~kg} \mathrm{~m}^{-3}$, $0.426 \mathrm{~m} \mathrm{~s}^{-1}$; corn pollen: $87 \mu \mathrm{m}, 1000 \mathrm{~kg} \mathrm{~m}^{-3}, 0.192 \mathrm{~m} \mathrm{~s}^{-1}$; copper beads: $46.6 \mu \mathrm{m}, 8900 \mathrm{~kg} \mathrm{~m}^{-3}, 0.471 \mathrm{~m} \mathrm{~s}^{-1}$. The results can be found in Astrup (2016).

\subsection{Csanady}

Outdoor test with glass beads of 0.1 and $0.2 \mathrm{~mm}$ diameter falling from an $18 \mathrm{~m}$ high tower in 8 (to 15) $\mathrm{mph}$ wind at the $18 \mathrm{~m}$ and collected on adhesive strips laid out on $1 \mathrm{~m}$ high tables on four 40 degree arcs, 55, 92, 128, respectively $165 \mathrm{~m}$ downstream the tower. Free fall speeds of 0.5 respectively $1.3 \mathrm{~m} \mathrm{~s}^{-1}$. The results can be found in Astrup (2016).

\section{Inclusion in the RIMPUFF dispersion program}

Doing an overall best, the Csanady correlation was selected for inclusion in the RIMPUFF program, (Mikkelsen et al., 1984; Thykier-Nielsen et al., 1999), and here it has been tested with particles with free fall velocities $0.00003,0.025,0.24$, and $0.49 \mathrm{~m} \mathrm{~s}^{-1}$ on two meteorological cases, one with stable atmospheric stratification, one with an unstable, release height: $50 \mathrm{~m}$. It turns out, that a free fall velocity of $0.025 \mathrm{~m} \mathrm{~s}^{-1}$ doesn't make these particles disperse any slower than the $0.00003 \mathrm{~m}$ $\mathrm{s}^{-1}$ particles, while the 0.24 and $0.49 \mathrm{~m} \mathrm{~s}^{-1}$ free fall particles disperse somewhat slower in the stable situation, but almost not in the unstable atmosphere with a relatively large vertical turbulence component. In the stable situation these heavier particles however fall to the ground very fast, for which reason their slower dispersion does not make much change to the deposit concentrations.

\section{Conclusion}

Fitted against wind tunnel tests of Wells and Stock (1983), the Csanady (1963) model for dispersion of larger and heavier particles than aerosols does very well against all the tests of Wells and Stokes, against wind tunnel tests of Snyder and Lumley (1971) and reasonably against the test of Csanady (1964) in the free atmosphere. The Astrup parameterization also does very well against the wind tunnel tests, but not so well against the Csanady free atmosphere tests.

Of the tested parameterizations the Csanady model seems to do an overall best and is therefore used for implementation in the RIMPUFF dispersion program.

However, as shown with this, the effect of particle fall velocity is much higher for the deposition rate than for the dispersion discrepancies. Particles heavy enough to show a measurable decrease of dispersion falls to the ground before much dispersion takes place, and particles light enough to not fall out immediately, disperse almost like aerosols.

Acknowledgement. The research leading to these results has received funding from the European Atomic Energy Community Seventh Framework Programme FP7/2012 under grant agreement no. 323287.

\section{References}

Astrup P. (2016) Atmospheric dispersion of particles larger and heavier than aerosols. PREPARE(WP4)-(3)-01.

Carruthers D.J., Holroyd R.J., Hunt J.C.R., Weng W.-S., Robins A. G., Apsley D.D., Smith F.B., Thomson D.J., Hudson B. (1992) UK atmospheric dispersion modelling system. In: Air Pollution Modelling and its Application IX (H. van Dop, G. Kallos, Eds.), pp. 15-28. Plenum Press, New York.

Csanady G.T. (1963) Turbulent diffusion of heavy particles in the atmosphere, J. Atmos. Sci. 21, 201-208.

Csanady G.T. (1964) An atmospheric dust fall experiment, J. Atmos. Sci. 21, 222-225.

Gosman A.D., Ioannides E. (1981) Aspects of computer simulation of liquid-fueled combustors. AIAA paper 81-0323.

Ichard M., Melheim J. (2010) Dispersion of heavy particles in turbulent-like flows. In: 7th International Conference on Multiphase Flow, 2010. URL: http://ufdc.ufl.edu/UF00102023/00180.

Mikkelsen T., Larsen S.E., Thykier-Nielsen S. (1984) Description or the Risø Puff diffusion model, Nucl. Technol. 67, 56-65.

Shuen J.-S., Chen L.-D., Faeth G.M. (1983) Evaluation of a stochastic model of particle dispersion in a turbulent round jet, AIChE J. 29 (1), 167-170.

Snyder W.H., Lumley J.L. (1971) Some measurements of particle velocity autocorrelation functions in a turbulent flow, J. Fluid Mech. 48 (1), 41-71.

Taylor G.I. (1922) Diffusion by continuous movements, Proc. Lond. Math. Soc. s2-20 (1), 196-212.

Thykier-Nielsen S., Deme S., Mikkelsen T. (1999) Description of the Atmospheric Dispersion Module RIMPUFF. http://www.rodos.fzk. de/Documents/Public/CD1/Wg2_CD1_General/WG2_TN98_02. pdf.

Walklate P.J. (1987) A random-walk model for dispersion of heavy particles in turbulent air flow, Boundary-Layer Meteorol. 39, 175-190. 
Wells M.R., Stock D.E. (1983) The effects of crossing trajectories on the dispersion of particles in a turbulent flow, J. Fluid Mech. 136, 31-62.
Yudine M.I. (1959) Physical considerations on heavy-particle diffusion. In: Advances in Geophysics, Vol. 6, pp. 185-191. Academic Press, New York.

Cite this article as: P. Astrup. Dispersion and fall out of heavier particles. Radioprotection 51(HS2), S113-S115 (2016). 